\title{
Cyclosporin-A does not affect skeletal muscle mass during disuse and recovery
}

M.S. Aoki ${ }^{1,2}$,

E.H. Miyabara ${ }^{1}$,

A.G. Soares ${ }^{1}$,

T.F. Salvini ${ }^{3}$

and A.S. Moriscot ${ }^{1}$
Correspondence

A.S. Moriscot

Laboratório de Plasticidade Muscular

Departamento de Biologia Celular

e do Desenvolvimento, ICB, USP

Av. Lineu Prestes, 1524

05508-900 São Paulo, SP

Brasil

E-mail: moriscot@usp.br

Research supported by FAPESP

(No. 03/00431-0).

...............................

Received March 15, 2005

Accepted September 9, 2005

$\ldots \ldots \ldots \ldots \ldots \ldots \ldots$
${ }^{1}$ Departamento de Biologia Celular e Desenvolvimento, Instituto de Ciências Biomédicas, Universidade de São Paulo, São Paulo, SP, Brasil ${ }^{2}$ Laboratório de Fisiologia do Exercício, Faculdade de Educação Física, Centro Universitário das Faculdades Metropolitanas Unidas, São Paulo, SP, Brasil ${ }^{3}$ Departamento de Fisioterapia, Universidade Federal de São Carlos, São Carlos, SP, Brasil

\begin{abstract}
Cyclosporin-A (CsA) is an immunosuppressive drug that acts as an inhibitor of calcineurin, a calcium phosphatase that has been suggested to play a role in skeletal muscle hypertrophy. The aim of the present study was to determine the effect of CsA administration (25 $\mathrm{mg} \mathrm{kg}^{-1} \mathrm{day}^{-1}$ ) on skeletal muscle mass and phenotype during disuse and recovery. Male Wistar rats received vehicle $(\mathrm{N}=8)$ or $\mathrm{CsA}(\mathrm{N}=$ 8) during hind limb immobilization $(\mathrm{N}=8)$ and recovery $(\mathrm{N}=8)$. Muscle weight (dry/wet) and cross-sectional area were evaluated to verify the effect of CsA treatment on muscle mass. Muscle phenotype was assessed by histochemistry of myosin ATPase. CsA administration during immobilization and recovery did not change muscle/body weight ratio in the soleus (SOL) or plantaris (PL). Regarding muscle phenotype, we observed a consistent slow-to-fast shift in all experimental groups (immobilized only, receiving CsA only, and immobilized receiving CsA) as compared to control in both SOL and $\mathrm{PL}(\mathrm{P}<$ 0.05). During recovery, no difference was observed in SOL or PL fiber type composition between the experimental recovered group and recovered group receiving CsA compared to their respective controls. Considering the muscle/body weight ratio, CsA administration does not maximize muscle mass loss induced by immobilization. Our results also indicate that $\mathrm{CsA}$ fails to block skeletal muscle regrowth after disuse. The present data suggest that calcineurin inhibition by CsA modulates muscle phenotype rather than muscle mass.
\end{abstract}

Key words

- Calcineurin

- Immobilization

- Recovery

- Skeletal muscle

- Hypertrophy

- Cyclosporin-A

\section{Introduction}

Cyclosporin-A (CsA) is an immunosuppressive oligopeptide extensively used in organ transplantation and autoimmune diseases $(1,2)$. It has been demonstrated that CsA is a potent inhibitor of calcineurin, a key enzyme involved in the regulation of calcium-dependent pathways $(3,4)$. The best characterized role of calcineurin is the transduction of immune cell activation via translocation of the transcription factor nuclear factor of activated T-cells (NFAT) into the nucleus and activation of target genes (5). It 
has been shown that calcineurin plays an important role in certain aspects of muscle plasticity, including hypertrophy, phenotype determination and regeneration (6-9).

In the myocardium, Sussman et al. (6) demonstrated that the inhibition of calcineurin by CsA blocked hypertrophy induced by overload. Skeletal muscle is also a target of CsA, causing muscle weakness, myalgia and increase of plasma creatine kinase (1).

Some initial data using an in vitro approach $(7,8)$ strongly supported the idea that skeletal muscle hypertrophy is dependent on calcineurin activity. Subsequently, an in vivo study conducted by Dunn and co-workers (10) involving the ablation model reinforced the idea that calcineurin controls skeletal muscle mass. More recent in vivo studies have suggested that calcineurin is mostly involved in fiber type determination rather than hypertrophy (11-13).

However, Mitchell et al. (14) suggested that CsA administration interferes with muscle mass maintenance and regrowth. According to their findings, CsA differentially affects muscle mass in a muscle-specific manner. For example, only the plantaris (PL) muscle (mainly composed of fasttwitch fibers) suffered a decrease in fiber cross-sectional area when a high dose (25 $\mathrm{mg} / \mathrm{kg}$ ) was used.

Recently, skeletal muscle mass and strength have been linked to health and wellness (1416). Metter et al. (16) demonstrated that in elderly men lower grip strength is associated with an increased risk of mortality. It is well established that disuse promotes hypotrophy and phenotype alterations in skeletal muscle $(15,17)$. Therefore, the understanding of molecular mechanisms involved in muscle mass maintenance and growth is crucial for developing strategies to attenuate muscle wasting and ensure quality of life of patients with hypokinesia conditions (e.g., elderly adults, patients submitted to long-term bed rest, athletes recovering from surgery/injury). The aim of the present study was to address the effect of CsA administration ( $25 \mathrm{mg} \mathrm{kg}^{-1}$ day $\left.^{-1}\right)$ on skeletal muscle mass and phenotype during disuse and recovery.

In order to induce muscle atrophy we submitted the animals to a period of 1 week of immobilization followed by 2 weeks of recovery during which the animals were allowed to move freely. This experimental design permitted us to assess the effect of calcineurin inhibition by CsA during disuse and regrowth of skeletal muscle.

\section{Material and Methods}

\section{Animals}

Male adult Wistar rats weighing $220 \mathrm{~g}$, were obtained from the animal breeding facility of the Institute of Biomedical Sciences, University of São Paulo. The animals were maintained on a constant 12:12-h ligh:dark cycle in metabolic cages, and received water and rat chow (Nuvilab ${ }^{\circledR}$, Colombo, PR, Brazil) ad libitum. The animals were anesthetized by intraperitoneal injection of a mixture of ketamine $(30 \mathrm{mg} / \mathrm{kg}$ body weight) and xylazine (10 mg kg body weight) before the immobilization procedure. The experimental protocol (\#097/2002) was approved by the Institute of Biomedical Sciences Ethics Committee for Animal Research, University of São Paulo.

\section{Hind limb immobilization procedure and CsA administration}

Monolateral hind limb immobilization was performed in the left limb of each animal by applying a cast with total plantar extension (18). The PL and soleus (SOL) muscles remained in the shortened position for 7 days, since it has been demonstrated that the most pronounced decrease in muscle mass occurs after 7 days (19). The cast was wrapped with a fine-meshed steel net to prevent chewing (20). Great care was taken to make sure that the cast did not cause 
ischemia. In order to determine the effect of CsA during immobilization we used animals that were immobilized for 7 days $(\mathrm{N}=8)$ and animals receiving CsA prior to and following the immobilization procedure $(\mathrm{N}=8)$. To test the hypothesis that CsA interferes with regrowth of skeletal muscle after immobilization, we used animals immobilized for 7 days and subsequently allowed to recover for 14 days $(\mathrm{N}=8)$ and animals receiving CsA during recovery $(\mathrm{N}=8)$. In order to assess the effect of CsA per se, we injected 2 groups of animals with CsA for 14 days, $(\mathrm{N}$ $=8$ ). Also, two groups of age-matched animals were injected with $0.9 \%$ saline and used as controls $(\mathrm{N}=8)$.

CsA was injected intraperitoneally daily $(25 \mathrm{mg} / \mathrm{kg}$ body weight, fractionated into 2 injections). It has been shown that similar doses of CsA lead to a significant inhibition of calcineurin activity (14). Dunn et al. (21) demonstrated a dose-dependent effect of CsA on calcineurin activity, with a significant decrease $(65 \%)$ in calcineurin activity being observed after a high dose of CsA.

\section{Analysis of gene expression}

Isolation of total RNA. Total RNA was isolated from SOL and extensor digitorum longus samples using the Trizol reagent (Invitrogen, Carlsbad, CA, USA) according to manufacturer recommendations. RNA concentrations were determined by measuring absorbance at $260 \mathrm{~nm}$. RNA purity was determined by calculating the ratio of absorbance at 260 and $280 \mathrm{~nm}$, and by ethidium bromide staining.

Reverse transcription. One microgram of total RNA was typically used in a reaction containing oligo dt $(500 \mu \mathrm{g} / \mathrm{mL}), 10 \mathrm{mM}$ of each dNTP, 5X First-Strand buffer, 0.1 M DTT, and $200 \mathrm{U}$ of reverse transcriptase (SuperScript II, Invitrogen). Reverse transcription was performed at $70^{\circ} \mathrm{C}$ for $10 \mathrm{~min}$, followed by $42^{\circ} \mathrm{C}$ for $60 \mathrm{~min}$, and $10 \mathrm{~min}$ at $95^{\circ} \mathrm{C}$.
Real time PCR. The technique used to estimate the relative values of mRNA levels of NFATc1 comparing CsA-receiving and control samples is based on real time detection of PCR products by measuring fluorescence quantified with the ABI Prism 5700 sequence detector (Applied Biosystems, Foster City, CA, USA), based on current methodology (9).

\section{Tissues samples}

The muscles (SOL and PL) were removed and weighed. Subsequently, the muscles were quickly frozen in isopentane cooled in liquid nitrogen, and stored at $-70^{\circ} \mathrm{C}$ for later histological assays. To assess the dry weight, a small aliquot of each muscle was weighed and then dried for $48 \mathrm{~h}$ at $80^{\circ} \mathrm{C}$.

\section{Histochemistry of myosin ATPase}

SOL and PL muscles were removed, weighed, immediately frozen in melting isopentane, and stored in a freezer at $-70^{\circ} \mathrm{C}$. Frozen muscles were cut into $10-\mu \mathrm{m}$ crosssections through the proximal to distal region using a cryostat (Leica CM3050, Nussloch, Germany). Alternate serial cross-sections were obtained in the proximal and middle regions of both muscles incubated for myofibrillar ATPase activity after alkali (ATPase, $\mathrm{pH}$ 10.3) or acid pre-incubation (ATPase, pH 4.3) (20,22). The myosin ATPase reaction is used to identify the muscle type fibers. For this assay, ATP is the reaction energy source and substrate, $\mathrm{P}_{\mathrm{i}}$ is the reaction product, and myosin is the enzyme. Since $P_{i}$ is invisible histochemically, the assay requires that $P_{i}$ be chemically reacted with calcium $(\mathrm{Ca})$ in order to form the precipitate calcium phosphate $\left(\mathrm{CaPO}_{4}\right.$, limestone). Subsequent steps in the process convert $\mathrm{CaPO}_{4}$ into cobalt sulfide $\left(\mathrm{CoS}_{2}\right)$, which is brownish-black, more easily visible, and less soluble. Thus, effectively, as $\mathrm{P}_{\mathrm{i}}$ is released by the myosin molecule's consump- 
tion of ATP, a brownish-black product is deposited on the muscle tissue section. Fastcontracting muscle fibers hydrolyze ATP faster than slow-contracting fibers. Therefore, fast-contracting fibers appear dark histochemically, and slow-contracting fibers appear light. When this method is used together with pre-incubation steps to accentuate or reverse this pattern, the myosin ATPase assay can be used to distinguish between fast- and slow-contracting muscle fibers. Type I fibers react deeply after acid preincubation at $\mathrm{pH} 4.3$, and lightly after alkali pre-incubation at $\mathrm{pH} 10.3$. The inverse occurs with type II muscle fibers (23). The incidence of muscle fiber types I, II and intermediate and muscle fiber cross-sectional areas was evaluated on a digitizing unit connected to a computer (Image Pro-plus, Media Cybernetic, Silver Spring, MD, USA). A total of $\sim 1500$ fibers were counted and classified according to ATPase activity.

\section{Cross-sectional area}

After classification, the cross-sectional area of all fibers ( 1500 per group) was determined using a microscope (Nikon Eclipse E600, Fukuoka, Japan) equipped with

Table 1. Effect of cyclosporin-A (CsA) administration on rat soleus (SOL) and plantaris $(\mathrm{PL})$ muscles during immobilization.

\begin{tabular}{|c|c|c|c|c|}
\hline & Control & Immobilized & CsA & $\begin{array}{c}\text { CsA + } \\
\text { immobilized }\end{array}$ \\
\hline \multicolumn{5}{|c|}{ Body weight (g) } \\
\hline Initial & $227.8 \pm 5.1$ & $223.8 \pm 6.5$ & $221.3 \pm 8.2$ & $219.5 \pm 8.5$ \\
\hline Final & $268.1 \pm 7.5^{\mathrm{a}}$ & $265.0 \pm 3.9^{a}$ & $231.5 \pm 7.3^{b, c}$ & $229.5 \pm 5.8^{b, c}$ \\
\hline \multicolumn{5}{|c|}{ Muscle/body weight $(\mathrm{mg} / \mathrm{g})$} \\
\hline SOL & $0.38 \pm 0.01$ & $0.25 \pm 0.01^{b}$ & $0.39 \pm 0.01$ & $0.28 \pm 0.01^{b, d}$ \\
\hline PL & $0.89 \pm 0.02$ & $0.70 \pm 0.02^{b}$ & $0.88 \pm 0.04$ & $0.72 \pm 0.02^{b, d}$ \\
\hline \multicolumn{5}{|c|}{ Dry weight/wet weight (\%) } \\
\hline SOL & $29.3 \pm 1.5$ & $28.2 \pm 1.4$ & $27.1 \pm 0.9$ & $29.4 \pm 2.6$ \\
\hline PL & $27.1 \pm 2.1$ & $27.8 \pm 1.4$ & $25.8 \pm 1.1$ & $28.4 \pm 1.0$ \\
\hline
\end{tabular}

Data are reported as mean \pm SD for 8 animals in each group.

aP $<0.05$ compared to initial body weight; ${ }^{b} \mathrm{P}<0.05$ compared to control; ${ }^{\mathrm{C}} \mathrm{P}<0.05$ compared to immobilized; ${ }^{\mathrm{d}} \mathrm{P}<0.05$ compared to CsA (ANOVA and Tukey test). a digital video camera and Image software (Image Pro-plus, Media Cybernetic).

\section{Statistical analysis}

For body weight, muscle body weight ratio, cross-sectional area, and fiber type determination, multiple comparisons of group mean values were performed by analysis of variance (ANOVA) followed by the Tukey test to compare the mean values of all groups. The Student $t$-test was applied to gene expression data. For all comparisons, a $\mathrm{P}$ value below 5\% was considered significant.

\section{Results}

\section{Effect of CsA administration during immobilization}

Body weight. CsA administration alone reduced body weight gain $(\sim 14 \%, \mathrm{P}<0.05)$ compared to control. Similarly, CsA combined with immobilization also decreased body weight gain when compared to the group only immobilized $(\sim 14 \%, \mathrm{P}<0.05$; Table 1).

Muscle weight. Immobilization successfully promoted muscle atrophy (SOL: $35 \%$, $\mathrm{P}<0.01$; PL: $21 \%, \mathrm{P}<0.05)$. A similar atrophy was observed in the immobilized group receiving CsA (SOL: $28 \%, \mathrm{P}<0.01$; PL: $18 \%, \mathrm{P}<0.05)$. However, we observed no alteration in muscle/body weight ratios of PL and SOL in the immobilized group receiving CsA compared to the group only immobilized, suggesting a main effect of immobilization rather than of CsA administration on skeletal muscle mass (Table 1). Also, the dry/wet weight ratio did not differ significantly among groups.

Fiber type. With regard to SOL fiber phenotype, a significant decrease in the percentage of type I fibers was noted in the immobilized group $(66.3 \pm 1.9)$, in the group receiving CsA (68.6 \pm 1.8$)$ and in the immo- 
bilized group receiving CsA $(69.8 \pm 1.4)$ compared to control $(86.4 \pm 1.9, \mathrm{P}<0.05$; Figure 1 and Table 2). Also, a proportional increase in the percentage of type II fibers was detected in the same groups compared to control (Figure 1 and Table 2). Therefore, the association of immobilization and CsA administration did not produce any additive slow-to-fast shift (Figure 1 and Table 2). In the PL, immobilization significantly reduced type I fiber percentage compared to control $(15.9 \pm 2.1$ vs $8.1 \pm 1.5 \%$; $\mathrm{P}<0.05)$. Immobilization in association with CsA caused a further reduction in type I fiber percentage, suggesting an additive effect in PL (15.9 \pm 2.1 vs $4.8 \pm 0.9 \%$; $\mathrm{P}<0.01$; Figure 1 and Table 2).

Cross-sectional area. As expected, in the SOL and PL the most abundant fiber types showed a marked decrease (type I for SOL (27\%) and type II for PL (25\%)) in cross-sectional area induced by immobilization $(\mathrm{P}<0.01)$. A similar reduction in crosssectional area was observed in the immobilized group receiving CsA compared to the group only receiving CsA (type I for SOL (20\%) and type II for PL (23\%); P < 0.01; Table 2).

\section{Effect of CsA administration during recovery}

Body weight. As observed during immobilization, CsA administration during recovery from immobilization also impaired body weight gain $(\mathrm{P}<0.05$; Table 3$)$.

Muscle weight. The muscle/body weight ratio of SOL and PL was not affected by CsA administration during recovery. The dry-wet weight ratio also did not differ significantly among groups (Table 3 ).

Fiber type. Regarding fiber phenotype, the recovery period seemed to be effective in reestablishing the SOL muscle fiber type profile in all recovered groups including the CsA-receiving group. CsA administration per se, as expected, induced a slow-to-fast fiber type shift (a 17\% decrease in fiber type

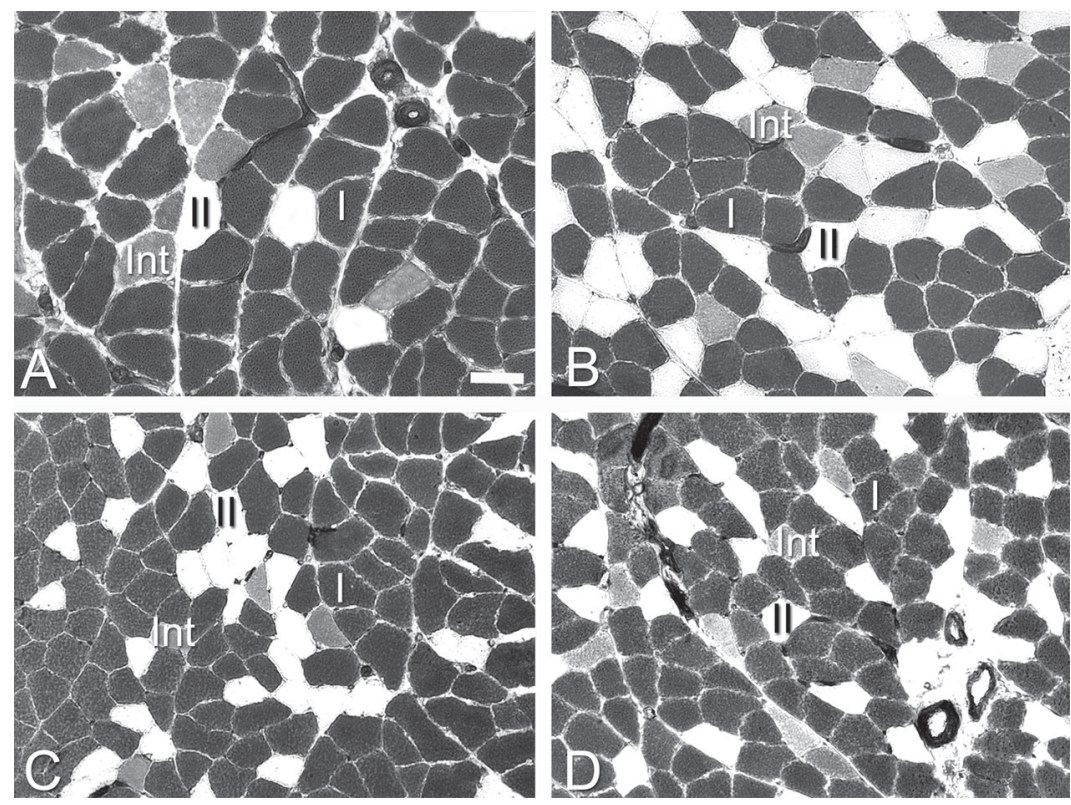

Figure 1. Histochemical ATPase activity at $\mathrm{pH} 4.39$ of a representative soleus muscle from the control group (A), the cyclosporin-A-receiving group (B), the immobilized group (C), and the immobilized group receiving cyclosporin-A (D). I, II and Int denote type I, type II and intermediate fibers, respectively. Solid bar $=50 \mu \mathrm{m}$ for all panels.

Table 2. Muscle fiber composition and cross-sectional area of soleus (SOL) and plantaris (PL) muscles of immobilized rats, of rats receiving cyclosporin-A (CsA), and of rats immobilized and receiving CsA.

\begin{tabular}{|c|c|c|c|c|}
\hline & Control & Immobilized & CsA & $\begin{array}{c}\text { CsA + } \\
\text { immobilized }\end{array}$ \\
\hline \multicolumn{5}{|l|}{ Fiber type (\%) } \\
\hline \multicolumn{5}{|l|}{ SOL } \\
\hline Type I & $86.4 \pm 1.9$ & $66.3 \pm 1.9^{a}$ & $68.6 \pm 1.8^{a}$ & $69.8 \pm 1.4^{a}$ \\
\hline Intermediate & $7.4 \pm 1.8$ & $10.7 \pm 0.8$ & $6.6 \pm 1.2$ & $5.3 \pm 0.7$ \\
\hline Type II & $6.1 \pm 1.4$ & $23.0 \pm 1.7^{a}$ & $24.9 \pm 1.4^{a}$ & $24.9 \pm 1.5^{a}$ \\
\hline \multicolumn{5}{|l|}{ PL } \\
\hline Type I & $15.9 \pm 2.1$ & $8.1 \pm 1.5^{a}$ & $10.8 \pm 1.8^{a}$ & $4.8 \pm 0.9^{a, b, c}$ \\
\hline Intermediate & $11.8 \pm 2.5$ & $18.7 \pm 3.4$ & $15.3 \pm 2.7$ & $22.5 \pm 1.1^{a}$ \\
\hline Type II & $72.2 \pm 4.1$ & $73.1 \pm 3.3$ & $73.8 \pm 2.3$ & $72.6 \pm 1.4$ \\
\hline \multicolumn{5}{|c|}{ Cross-sectional area $\left(\mu \mathrm{m}^{2}\right)$} \\
\hline \multicolumn{5}{|l|}{ SOL } \\
\hline Type I & $2905 \pm 984$ & $2140 \pm 727^{a}$ & $2699 \pm 750$ & $2167 \pm 585^{a}$ \\
\hline Intermediate & $1891 \pm 447$ & $1609 \pm 378$ & $1931 \pm 553$ & $1630 \pm 283$ \\
\hline Type II & $2091 \pm 552$ & $1686 \pm 336$ & $1971 \pm 553$ & $1618 \pm 471$ \\
\hline \multicolumn{5}{|l|}{ PL } \\
\hline Type I & $1755 \pm 675$ & $1285 \pm 408$ & $1453 \pm 296$ & $1104 \pm 275$ \\
\hline Intermediate & $2575 \pm 832$ & $2198 \pm 748$ & $2356 \pm 377$ & $2021 \pm 412$ \\
\hline Type II & $2104 \pm 398$ & $1592 \pm 402^{a}$ & $1826 \pm 388$ & $1409 \pm 424^{a}$ \\
\hline
\end{tabular}

Data are reported as mean \pm SD for 8 animals in each group. A total of $\sim 1500$ fibers were counted per group.

ap $<0.05$ compared to control; ${ }^{\text {bP }}<0.05$ compared to immobilized; ${ }^{\mathrm{c} P}<0.05$ compared to CsA (ANOVA and Tukey test). 
I in SOL, $\mathrm{P}<0.05$ ) (Table 4). In addition, no difference was observed in PL fiber type composition after recovery compared to control animals (Table 4).

Table 3. Effect of cyclosporin-A (CsA) administration on rat soleus (SOL) and plantaris $(\mathrm{PL})$ muscles during recovery.

\begin{tabular}{|c|c|c|c|c|}
\hline & Control & Recovered & CsA & $\begin{array}{c}\text { Recovered } \\
+ \text { CsA }\end{array}$ \\
\hline \multicolumn{5}{|c|}{ Body weight (g) } \\
\hline Initial & $224.9 \pm 6.6$ & $229.6 \pm 8.9$ & $225.4 \pm 8.6$ & $222.4 \pm 9.6$ \\
\hline Final & $279.4 \pm 9.2^{\mathrm{a}}$ & $283.6 \pm 9.9^{a}$ & $242.2 \pm 7.5^{b, c}$ & $239.5 \pm 8.5^{b, c}$ \\
\hline \multicolumn{5}{|c|}{ Muscle/body weight (mg/g) } \\
\hline SOL & $0.36 \pm 0.01$ & $0.33 \pm 0.01$ & $0.38 \pm 0.01$ & $0.34 \pm 0.01$ \\
\hline $\mathrm{PL}$ & $0.88 \pm 0.01$ & $0.80 \pm 0.01$ & $0.87 \pm 0.02$ & $0.79 \pm 0.03$ \\
\hline \multicolumn{5}{|c|}{ Dry weight/wet weight (\%) } \\
\hline SOL & $27.9 \pm 0.9$ & $26.4 \pm 1.3$ & $25.2 \pm 1.9$ & $28.2 \pm 1.4$ \\
\hline $\mathrm{PL}$ & $27.5 \pm 0.5$ & $28.9 \pm 0.4$ & $27.5 \pm 0.8$ & $27.2 \pm 0.6$ \\
\hline
\end{tabular}

Data are reported as mean \pm SD for 8 animals in each group.

aP $<0.05$ compared to initial body weight; ${ }^{b} \mathrm{P}<0.05$ compared to control; ${ }^{\mathrm{C}} \mathrm{P}<0.05$ compared to recovered (ANOVA and Tukey test).

Table 4. Muscle fiber composition and cross-sectional area of the soleus (SOL) and plantaris $(\mathrm{PL})$ muscles of recovered rats, rats receiving cyclosporin-A (CsA), and recovered rats receiving $\mathrm{CsA}$.

\begin{tabular}{lrrrr}
\hline & Control & Recovered & CsA & $\begin{array}{c}\text { Recovered } \\
+ \text { CsA }\end{array}$ \\
& & & & \\
\hline $\begin{array}{l}\text { Fiber type (\%) } \\
\text { SOL }\end{array}$ & & & & \\
$\quad$ Type I & $81.9 \pm 2.9$ & $72.5 \pm 1.7$ & $66.2 \pm 1.9^{\mathrm{a}}$ & $71.6 \pm 2.6$ \\
$\quad$ Intermediate & $6.2 \pm 2.0$ & $11.4 \pm 2.1$ & $16.1 \pm 1.8^{\mathrm{a}}$ & $11.2 \pm 1.5$ \\
$\quad$ Type II & $11.9 \pm 2.3$ & $16.0 \pm 2.3$ & $17.6 \pm 3.3$ & $17.1 \pm 1.1$ \\
PL & & & & \\
$\quad$ Type I & $11.1 \pm 3.4$ & $7.3 \pm 1.9$ & $7.0 \pm 2.5$ & $5.1 \pm 1.6$ \\
$\quad$ Intermediate & $14.2 \pm 3.2$ & $19.9 \pm 2.0$ & $21.4 \pm 1.8$ & $24.3 \pm 1.5$ \\
$\quad$ Type II & $74.7 \pm 2.7$ & $73.2 \pm 3.2$ & $71.6 \pm 3.3$ & $70.5 \pm 1.1$ \\
Cross-sectional area $\left(\mu m^{2}\right)$ & & & \\
SOL & & & & \\
$\quad$ Type I & $2828 \pm 804$ & $2730 \pm 795$ & $2677 \pm 656$ & $2573 \pm 554$ \\
$\quad$ Intermediate & $2121 \pm 434$ & $2382 \pm 555$ & $2266 \pm 579$ & $2168 \pm 579$ \\
$\quad$ Type II & $2207 \pm 582$ & $2273 \pm 927$ & $2344 \pm 637$ & $2231 \pm 435$ \\
PL & & & & \\
$\quad$ Type I & $2237 \pm 214$ & $1868 \pm 301$ & $1789 \pm 546$ & $1571 \pm 444$ \\
$\quad$ Intermediate & $3058 \pm 308$ & $2314 \pm 718$ & $2799 \pm 609$ & $2608 \pm 529$ \\
$\quad$ Type II & $2817 \pm 402$ & $2787 \pm 624$ & $2448 \pm 537$ & $2232 \pm 365^{\mathrm{a}, \mathrm{b}}$ \\
\hline
\end{tabular}

Data are reported as mean \pm SD for 8 animals in each group. A total of $\sim 1500$ fibers were counted per group.

aP $<0.05$ compared to control; b $P<0.05$ compared to recovered (ANOVA and Tukey test).
Cross-sectional area. In the SOL, the cross-sectional areas of all fiber types (I, intermediate and II) were similar in all groups. PL fiber type II cross-sectional area was smaller $(20 \%, \mathrm{P}<0.05)$ in the recovered group receiving CsA compared to the recovered group not receiving CsA (Table 4).

\section{NFATc1 expression}

In order to demonstrate the impact of CsA administration on the calcineurin pathway, we compared the expression of NFATc1 (a calcineurin substrate) in the CsA-treated group and the control group. A marked reduction $(70 \%, \mathrm{P}<0.001)$ of NFATc1 was noted in the CsA-receiving group compared to control (Figure 2).

\section{Discussion}

The results of the present study show that immobilization modulates muscle mass and phenotype. However, CsA administration did not maximize the responses triggered by immobilization. In addition, CsA did not impair skeletal muscle regrowth after disuse.

The dephosphorylation of NFAT by calcineurin allows its translocation to the nucleus and the subsequent activation of target genes. In order to verify the effect of CsA administration on the calcineurin pathway, we assessed the expression of NFATc1 and observed that CsA treatment resulted in decreased NFATc1 expression. Our findings agree with those of Dupont-Versteegden and colleagues (11), who reported a decrease in NFAT expression after CsA treatment in rats submitted to hind limb suspension. As expected, these investigators also observed that CsA treatment blocked NFAT translocation (11).

The effects of calcineurin inhibition by CsA on skeletal muscle are still not well established; however, some early case reports have predicted a possible link between 
CsA and skeletal muscle myopathies in patients after kidney/heart transplantation or in the management of Grave's disease $(24,25)$. Dunn et al. (10) showed that skeletal muscle hypertrophy can be blocked by CsA in the ablation model. In contrast, other studies failed to associate CsA administration with skeletal muscle mass maintenance in different experimental approaches, including the use of myotoxins and transgenic animals $(13,25-27)$. It is noteworthy that a dosage considered to be low $(5 \mathrm{mg} / \mathrm{kg}$ ) was used in these studies. It is argued that low doses $(\sim 5$ $\mathrm{mg} / \mathrm{kg}$ ) of CsA cause only a mild reduction $(20 \%)$ in calcineurin activity and therefore are not as effective in preventing skeletal muscle mass gain as doses above $25 \mathrm{mg} / \mathrm{kg}$, which inhibit calcineurin activity by $65 \%$ (21). Conversely, it has been stated that calcineurin activity is not altered during muscle hypertrophy, arguing against a role of calcineurin in hypertrophy. Furthermore, transgenic overexpression of constitutively active calcineurin does not cause hypertrophy (28).

Accordingly, Dupont-Versteegden et al. (11) demonstrated that CsA administration did not block the regain of SOL (a slowtwitch muscle) mass induced by reload interventions after disuse models (hind limb suspension and spinal cord transection). We have used an immobilization model to address the role of CsA (a calcineurin inhibitor, at the dose of $25 \mathrm{mg} / \mathrm{kg}$ ) in skeletal muscle mass loss and recovery in fast- and slow-twitch muscles and also investigated fiber type transitions. Our results clearly show that neither mass loss nor regain is affected by CsA administration when the muscle/body weight ratio is considered.

In another study, Mitchell et al. (14) showed that CsA administration affects PL muscle mass maintenance when doses starting at $25 \mathrm{mg} / \mathrm{kg}$ are used, although the muscle/ body weight ratio was not taken into consideration. Furthermore, in their study, CsA administration decreased fiber cross-sec- tional area only in the PL, suggesting a fiber type-specific muscle response. The rationale behind this finding is that, under normal conditions, calcineurin activity is higher in fiber type I than in type II and therefore CsA administration is more deleterious to muscles (such as the PL) mainly composed of fast fibers.

In agreement with the study of Mitchell et al. (14), our results also demonstrate that, during recovery, PL absolute weight regain and cross-sectional area were decreased by CsA. However, when the muscle/body weight ratio was considered, no differences were seen after disuse and recovery in both either the SOL or PL of animals treated with CsA. Since it is clear that the body weight gain was attenuated by CsA administration, we conclude that CsA induces not only a specific tissue response, but also more extensive effects. We emphasize that the tissue weight-to-body weight ratio is crucial if one wants to address the role of CsA at a particular site.

General toxicity has been attributed to high doses of CsA $(24,29)$. Irintchev et al. (30) demonstrated a decrease in body weight gain of mice in the first 2 weeks of administration. In the study conducted by Dunn et al. (10), no alteration in body weight was reported after CsA administration. Similarly to the study of Irintchev et al. (30) we have observed a decreased body weight gain caused by CsA. This decrease in body weight is not related to changes in food consumption since no difference was observed in any of the CsA-receiving groups (CsA-receiving group, immobilized CsA-receiving group and

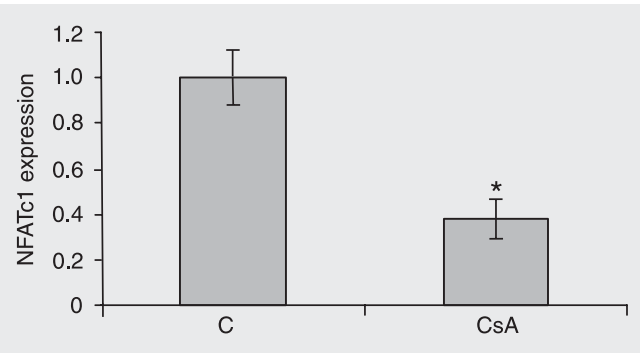

Figure 2. Soleus muscle NFATc1 gene expression in control (C) and cyclosporin-Areceiving (CsA) groups. Data are reported in arbitrary units for 8 animals in each group. The columns indicate the mean \pm SD for 8 samples. ${ }^{*} \mathrm{P}<0.01 \mathrm{com}$ pared to control (ANOVA and Tukey test). 
recovered CsA-receiving group) regarding food intake compared to control groups. At present, the overall mechanisms underlying minimization of weight gain caused by CsA are not clear. The inconsistencies found in these studies, both using mice, might be due to the different dosages of CsA used, which were 50 and $25 \mathrm{mg} / \mathrm{kg}$, respectively. In our experience, when a high dose $(50 \mathrm{mg} / \mathrm{kg})$ is used in rats, a high mortality rate (above $70 \%$ ) is observed (data not shown).

The controversies regarding the role of CsA in skeletal muscle mass are likely to be due to different experimental approaches, such as the dose and period of CsA administration, the animal model used to induce hypertrophy (e.g., ablation of synergistic muscles and tenotomy), the animal species (rat $v s$ mice) and the muscle mass parameters analyzed (absolute weight, cross-sectional area, muscle/body weight ratio).

Other studies have suggested that calcineurin is mostly involved in muscle fiber type determination rather than hypertrophy (11-13). Regarding this issue, our results corroborate the hypothesis that CsA administration and calcineurin inhibition determine changes in muscle fiber phenotype rather than hypertrophy. As expected, CsA administration per se induced a marked de- crease in type I fibers and this change was accompanied by an increase in type II and/or intermediate fibers. In addition, the combination of CsA administration and immobilization did not further induce slow-to-fast transitions. These results lead us to speculate that disuse may result in diminished calcineurin activity by a decrease of the $\mathrm{Ca}^{2+}$ fluctuations that occur during each contraction and relaxation cycle. Therefore, CsA may not cause additional phenotype shifts in immobilized muscles because calcineurin activity is already reduced.

The present data support the idea that CsA is not involved in muscle mass maintenance during disuse and recovery and that it is crucial to consider the muscle/body weight ratio to draw specific conclusions. Finally, we observed that CsA and disuse both induced marked phenotypic changes in skeletal muscle, although in a non-additive manner, supporting the notion that the calcineurin pathway plays a central role in fiber type determination.

\section{Acknowledgments}

We gratefully acknowledge the collaboration of Dr. Telma Maria Tenório Zorn.

\section{References}

1. Breil M \& Charriot $P$ (1999). Muscle disorders associated with cyclosporine treatment. Muscle and Nerve, 22: 1631-1636.

2. Schreiber SL \& Crabtree GR (1992). The mechanism of action of cyclosporin A and FK-506. Immunology Today, 13: 136-142.

3. Crabtree GR (1999). Generic signals and specific outcomes: signalling through Ca calcineurin, and NFAT. Cell, 96: 611-614.

4. Olson EN \& Williams RS (2000). Remodeling muscles with calcineurin. Bioessays, 22: 510-519.

5. Rao A, Luo C \& Hogan PG (1997). Transcription factors of the NFAT family: regulation and function. Annual Review of Immunology, 15: 707-747.

6. Sussman MA, Lim HW, Cambon N et al. (1998). Prevention of cardiac hypertrophy by calcineurin inhibition. Science, 281: 16901693.

7. Musaro A, Mccullagh KJ, Naya FJ et al. (1999). IGF-1 induces skeletal myocyte hypertrophy through calcineurin in association with GATA-2 and NF-ATc1. Nature, 400: 581-585.

8. Semsarian C, Wu MJ, Ju YK et al. (1999). Skeletal muscle hypertrophy is mediated by a $\mathrm{Ca}^{2+}$-dependent calcineurin signalling pathway. Nature, 400: 576-581.

9. Miyabara EH, Aoki MS, Soares AG et al. (2005). Expression of tropism-related genes in regenerating skeletal muscle of rats treated with cyclosporin-A. Cell and Tissue Research, 319: 479-489.

10. Dunn SE, Burns JL \& Michel RN (1999). Calcineurin is required for skeletal muscle hypertrophy. Journal of Biological Chemistry, 274: 21908-21912.

11. Dupont-Versteegden E, Knox M, Gurley CM et al. (2002). Maintenance of muscle mass is not dependent on the calcineurin-NFAT pathway. American Journal of Physiology, 282: C1387-C1395.

12. Schiaffino $S \&$ Serrano AL (2002). Calcineurin signaling and neural control of skeletal muscle fiber type and size. Trends in Pharmacological Sciences, 23: 569-575. 
13. Serrano AL, Murgia M, Pallafacchina G et al. (2001). Calcineurin controls nerve activity-dependent specification of slow skeletal muscle fibers but not muscle growth. Proceedings of the National Academy of Sciences, USA, 98: 13108-13113.

14. Mitchell PO, Mills ST \& Pavlath GK (2002). Calcineurin differentially regulates maintenance and growth of phenotypically distinct muscles. American Journal of Physiology, 282: C984-C992.

15. Machida S \& Booth FW (2004). Regrowth of skeletal muscle atrophied from inactivity. Medicine and Science in Sports and Exercise, 36: 52-59.

16. Metter EJ, Talbot LA, Schrager M et al. (2002). Skeletal muscle strength as a predictor of all-cause mortality in healthy men. Journal of Gerontology. Series A, Biological Sciences and Medical Sciences, 57: 359-365.

17. Booth FW (1982). Effect of limb immobilization on skeletal muscle. Journal of Applied Physiology, 52: 1113-1118.

18. Williams PE \& Goldspink G (1971). Longitudinal growth of striated muscle fibers. Journal of Cell Science, 9: 751-759.

19. Appell HJ (1986). Skeletal muscle atrophy during immobilization. International Journal of Sports Medicine, 7: 1-5.

20. Ansved T (1995). Effects of immobilization on the rat soleus muscle in relation to age. Acta Physiologica Scandinavica, 154: 291-302.

21. Dunn SE, Simard AR, Prud'Homme RA et al. (2002). Calcineurin and skeletal muscle growth. Nature Cell Biology, 4: E46.

22. Guth L \& Samaha FJ (1969). Qualitative differences between acto- myosin ATPase of slow and fast mammalian muscle. Experimental Neurology, 25: 138-163.

23. Brooke MH \& Kaiser KK (1970). Three "myosin adenosine triphosphatase" systems: the nature of their $\mathrm{pH}$ lability and sulfhydryl dependence. Journal of Histochemistry and Cytochemistry, 18: 670672.

24. Bennett WM \& Norman DJ (1986). Action and toxicity of cyclosporin. Annual Review of Medicine, 37: 215-224.

25. Biring MS, Fournier M, Ross DJ et al. (1998). Cellular adaptations of skeletal muscles to cyclosporine. Journal of Applied Physiology, 84: 1967-1975.

26. Bodine SC, Stitt TN, Gonzalez M et al. (2001). Akt/mTOR pathway is a crucial regulator of skeletal muscle hypertrophy and can prevent muscle atrophy in vivo. Nature Cell Biology, 3: 1014-1019.

27. Naya RJ, Mercer B, Shelton JM et al. (2000). Stimulation of slow skeletal muscle fiber gene expression by calcineurin in vivo. Journal of Biological Chemistry, 275: 4545-4548.

28. Yancopoulos GD \& Glass DJ (2002). Calcineurin and skeletal muscle growth. Nature Cell Biology, 4: E47.

29. Richter-Reichhelm HB \& Schulte AF (1998). Results of a cyclosporin A ring study. Toxicology, 129: 91-94.

30. Irintchev A, Zweyer M, Cooper RN et al. (2002). Contractile properties, structure and fiber phenotype of intact and regenerating slowtwitch muscles of mice treated with cyclosporin A. Cell and Tissue Research, 308: 143-156. 